\title{
Casos de criação e remotivação de lexias textuais em João Cabral de Melo Neto: crítica social, ironia e expressividade
}

\author{
Rosana Maria Sant'Ana Cotrim \\ Universidade Federal de Goiás (UFG), Goiânia, Goiás, Brasil \\ rocotrim@ufg.br
}

DOI: http://dx.doi.org/10.21165/el.v45i1.726

\begin{abstract}
Resumo
Este artigo tem por objetivo apresentar uma análise das criações e remotivações de lexias textuais, concebidas como uma forma de neologia estilística e como um recurso discursivo da poética de João Cabral de Melo Neto, escritor pernambucano teoricamente enquadrado no Modernismo brasileiro. A análise aponta que as unidades resultantes deste processo de criação lexical na poética cabralina e os respectivos efeitos de sentido por elas alcançados no nível do discurso expressam ironia e irreverência e vão ao encontro da temática abordada em cada contexto em que se inserem, de modo a reiterar o caráter de crítica histórico-social de sua obra e corroborar o processo de superação da dicotomia entre expressão e construção primado pelo poeta.
\end{abstract}

Palavras-chave: criação lexical literária; recurso discursivo; expressividade.

Cases of Creating and Remotivating Textual Lexias in João Cabral de Melo Neto: Social Criticism, Irony and Expressiveness

\begin{abstract}
This article aims to present an analysis about the creations and remotivations of textual lexias, conceived as a form of stylistic neology and as a discursive resource of the poetics of João Cabral de Melo Neto, a writer from Pernambuco who is theoretically framed in Brazilian Modernism. The analysis points out that the units resulting from this lexical creation process in Cabralian poetics and their respective effects of meaning achieved by them at the level of discourse express irony and irreverence. These units and effects also meet the theme approached in every context they are inserted into, in order to reiterate the character of historical and social criticism that Cabral's work reveals and to validate the process of overcoming the dichotomy between expression and construction transcended by the poet.
\end{abstract}

Keywords: literary lexical creation; discursive resource; expressiveness.

\section{Introdução}

No discurso literário, via de regra, as escolhas lexicais buscam resultados estéticos $^{1}$ inéditos que podem inclusive marcar uma época, um estilo. Dentre os modos

\footnotetext{
1 O termo "estético" é tomado neste contexto em dupla acepção: como relativo ao sentimento do belo oriundo da estética como estudo filosófico das condições e dos efeitos da criação artística; e como fruto do relacionamento entre a obra e o leitor, concebido por Jauss (2002, p. 100-102) em uma teoria fundada na 'recepção', cujo pressuposto consiste na recuperação da historicidade da literatura a partir do reconhecimento de seus intercâmbios com o público. Segundo esta teoria, a experiência estética compõese de três etapas, inter-relacionadas: a poiesis, pela qual se compreende que o recebedor participa da
} 
de operar tais escolhas estão as criações lexicais literárias, concebidas como um tipo de neologia estilística e compreendidas como um fenômeno estilístico da criatividade.

Mediadas, pois, pelas escolhas estilísticas, as criações lexicais literárias revelam um modo particular de expressividade no discurso. E, apesar de raramente incorporarem-se ao léxico de uma língua, justamente por atuarem no nível do discurso, elas provocam efeitos de sentido importantes dentro do enunciado que as tornam merecedoras de atenção.

Este trabalho tem por objetivo, portanto, analisar as criações e remotivações de lexias textuais encontradas, entre outros tipos de criações lexicais, na poética de João Cabral de Melo Neto $^{2}$ e, por essa via, demonstrar a expressividade e os efeitos de sentido por elas alcançados discursivamente.

A análise tem como bases teórico-metodológicas a Lexicologia para a recolha e classificação das unidades léxicas criadas, a Estilística Léxica para o reconhecimento e demonstração da sua expressividade e efeitos de sentido no discurso literário, e o Critério Lexicográfico para a sua atestação.

Como corpus de extração das unidades léxicas criadas foi utilizado um compêndio de obras do poeta, publicado em dois volumes intitulados, respectivamente, Serial e antes (1997a) e Educação pela pedra e depois (1997b), compostos de vinte livros de poesias. E para a atestação ou não do caráter neológico das mesmas, adotou-se como corpora de exclusão os dicionários Novo Aurélio (1975), o Dicionário Aurélio de Língua Portuguesa (2010), o Dicionário Houaiss de Língua Portuguesa, versão eletrônica 3.0 (2009) e o Dicionário Aurélio da Língua Portuguesa, versão eletrônica 7.0 (2010), considerados de grande representatividade no português brasileiro desde aproximadamente a terceira fase da literatura modernista produzida no Brasil até a atualidade.

Não obstante as limitações que cercam este critério de atestação no contexto das análises lexicológicas da neologia, principalmente no universo literário em razão da raridade de desneologização das criações lexicais literárias e, por conseguinte, da excepcionalidade de sua inserção num dicionário de língua, ele se faz necessário nesta análise porque permite o estabelecimento de um parâmetro temporal, espacial, social, cultural, ou outro, capaz de fornecer a objetividade e precisão desejadas para os resultados de uma pesquisa científica. E a escolha do referido escritor nesta análise se justifica pela compreensão de que a presença da neologia estilística representa um perfil iterativo que se quer desvelado em sua obra poética.

Para tanto, na sequência deste artigo serão expostos, respectivamente: uma abordagem sobre o fenômeno da criação lexical como um recurso de criatividade e expressividade no discurso literário; alguns apontamentos sobre autor e obra poética selecionados para a pesquisa; uma demonstração do modo como as criações e remotivações de lexias textuais, vistas como um tipo específico de criação lexical

produção do texto; a aisthesis, quando este alarga o conhecimento que o destinatário tem do mundo; e a katharsis, durante a qual ocorre o processo de identificação que afeta as possibilidades existenciais do leitor.

2 O presente trabalho retoma e adapta para esta publicação parte de nossas pesquisas para tese de doutorado, defendida junto ao Programa de Pós-Graduação em Linguística e Língua Portuguesa da Universidade Estadual Paulista, Campus de Araraquara (UNESP/FCLAr). 
literária, operam no discurso do referido autor; e, algumas considerações sobre a importância e os resultados do fenômeno para a sua poética.

\section{Criação lexical literária: a criati vidade no discurso}

Tradicionalmente, a neologia tem sido conceituada como a capacidade natural de criação e incorporação de novas unidades léxicas numa língua para a nomeação de novas experiências (fatos ou objetos). Isso é o que garante, em regra, a ampliação e/ou renovação do léxico de uma língua e lhe dá a etiqueta de neologia denominativa. Contudo, se aplicada ao discurso literário, a criação lexical assume papel diverso, de modo a suscitar sua observação e análise pela perspectiva da criatividade.

A criação lexical literária, compreendida no âmbito das escolhas do léxico real ou virtual da língua e concebida, a partir de Guilbert (1975, p. 41-42), como uma forma de neologia estilística em contraposição à neologia denominativa, pode ser definida como uma busca de expressividade das palavras ou das frases por meio das palavras, para traduzir ideias já existentes de maneira nova e marcar uma visão diferenciada ou pessoal do mundo. Essas marcas de pessoalidade são oriundas da faculdade da criação verbal e da liberdade de expressão e fazem da neologia estilística um recurso muito próprio à linguagem literária.

O papel expressivo que cabe às criações lexicais literárias as torna pouco aplicáveis a um contexto diferente, pontuando-lhes um caráter efềmero. Isso, sem dúvida, dificulta sua integração ao léxico da língua e faz com que elas permaneçam no nível do discurso para (re)motivarem-se a cada nova leitura.

Em contrapartida, a criação lexical literária, recoberta pelo caráter polissêmico e pluri-isotópico da linguagem conotativa típica da literatura, reflete a virtualidade do sistema e a criatividade do usuário da língua. O sistema dispõe de regras de formação de palavras e as disponibiliza para que o enunciador as aplique discursivamente, atendendo ao seu desejo de expressão e deixando transparecer as marcas de pessoalidade.

Embora o fenômeno da virtualidade seja concebido a partir da oposição saussuriana entre língua e fala, que compreendia a língua como o domínio das virtualidades e a fala como a realidade atual, reconhece-se que as marcas de pessoalidade que envolvem a criação lexical são adquiridas no quadro da experiência social e dentro dos limites da criação linguística.

Ocorre que a contestação da linguística centrada na língua e a consequente busca de compreensão dos atos de fala no contexto social, decorrentes das novas concepções da relação entre língua e fala, culminaram no final do século XX com a invocação ao aspecto discursivo da unidade do léxico, isto é, da palavra.

A articulação entre o linguístico e o social vincula a linguagem à ideologia. Sendo, pois, um "fenômeno ideológico por excelência" (BAKHTIN, 1997, p. 36), a palavra representa o modo mais puro e sensível da relação social. Por isso não deve ser tomada como abstração, mas como a materialização do "signo ideológico" que é movente, dialético por natureza. E, como as modificações da ideologia incidem sobre a língua, contrariamente ao que prescreve a concepção saussuriana, o seu caráter evolutivo adquire uma conotação positiva. 
Sob essa perspectiva, a língua não reside na mente do falante, nem é um sistema abstrato que está acima das condições sociais. Ela é um empreendimento conjunto e partilhado entre os falantes; é atividade social e, portanto, a forma suprema de enunciação. A enunciação repousa no diálogo social: só se enuncia em função de um interlocutor, ainda que potencial. Por isso a escolha das palavras dentro do discurso é determinada por diferentes variáveis de ordem intra e extralinguística. Nesse contexto, a palavra, galgando a função privilegiada de veiculadora de ideologia, além de unidade do léxico, assume a condição de unidade léxica dentro do discurso.

No que tange ao fenômeno da criação lexical, as ideias guilbertianas, ao tratarem das questões da neologia e, particularmente, das teorias dos modos de derivação, encontram aí um aporte para a mudança de perspectiva frente ao componente lexical:

A palavra é realmente um elemento lexical que se define através das realizações do discurso [...]. A transformação do esquema de frase em frase realizada supõe a comunicação entre um sujeito falante que enuncia a sequência sintática real e um ouvinte presente ou fictício que a recebe. Cada um destes seres de carne e de sangue é modalizado psicológica e sociologicamente, animado de motivações particulares dentro do diálogo; a língua é vista a partir de então como o instrumento de comunicação de seres pensantes, membros de uma comunidade linguística, dentro de uma situação dada e não mais como uma estrutura abstrata (GUILBERT, 1975, p. 126, tradução nossa). ${ }^{3}$

Assim concebida, a palavra deixa de ser uma unidade dentre a totalidade do léxico da língua para tornar-se um elemento de elocução de um indivíduo e, portanto, passível de variação quanto ao tipo de discurso e de possibilidade de nuançar a expressão. E à noção de "criatividade", amarrada à tradição cartesiana e governada por um sistema de regras, de princípios, de limitações, introduz-se a consideração das determinações enunciativas e socioculturais.

Isso acontece porque, embora Guilbert tenha analisado o fenômeno da criatividade pela referência explícita à perspectiva chomskyana colocando-a como um princípio constitutivo da língua, ele a aplica às estruturas sintáticas inserindo-a num quadro oposto ao racionalismo cartesiano. De fato, Guilbert era um linguista essencialmente preocupado com os problemas do léxico, porém suas bases fincadas no pensamento marxista procuram mostrar

[...] como a modificação do campo de aplicação - da sintaxe ao léxico - e a diferença de perspectiva ideológica - do idealismo cartesiano ao materialismo dialético - mudam profundamente o conceito inicial, e conduzem a uma problemática que inclui as relações entre língua, discurso e sociedade (BASTUJI, 1979, p. 12, tradução e grifos nossos). ${ }^{4}$

\footnotetext{
${ }^{3}$ Le mot est en effet part un élément lexical qui se définit à travers les realizations du discours [...]. La transformation du schéma de phrase en phrase réalisée suppose la communication entre un sujet parlant qui énonce la séquence syntaxique réelle et un auditeur présent ou fictif qui la reçoit. Chacun de ces êtres de chair et de sang est façonné psychologiquement et sociologiquement, animé de motivations particulières dans le dialogue; le langage apparait des lors comme l'instrument de communication d'êtres pensants, membres d'une communauté linguistique, dans une situation donné et non plus comme une struture abstraite.

4 [...] comment la modification du champ d'application - de la syntaxe au lexique - et la différence de perspective idéologique - de l'idéalisme cartésien au matérialisme dialectique - changeante profondément le concept initial, et conduisent à une problématique incluant les rapports entre langue, discours et société.
} 
O que, a princípio, poderia parecer uma justaposição de conceitos inconciliáveis - em linhas gerais, criatividade lexical versus materialismo histórico - é explicado dialeticamente na perspectiva guilbertiana através do funcionamento do sistema pelo qual as regras são tratadas em relação à sociedade.

Além disso, sob a perspectiva de uma "estilística sociológica" bakhtiniana, as criações lexicais literárias podem ser reconhecidas como recurso estilístico visto que "a forma e o conteúdo são indivisos no discurso concebido como fenômeno social - social em todos os campos de sua vida e em todos os seus elementos, da imagem sonora às camadas semânticas abstratas" (BAKHTIN, 2015, p. 21).

Em resumo, as criações lexicais funcionam como unidades discursivas responsáveis por traduzir a expressão do sentimento de quem a produz, mas também podem marcar uma época assinalando posições ideológicas. Além disso, o neologismo no discurso literário, como qualquer outra marca discursiva, aparece sempre ligado a uma situação de enunciação. Ressalte-se, daí, a possibilidade de se estabelecer, dentro de cada obra ou no conjunto de obras de um escritor, traços recorrentes capazes de demarcar uma preferência que as caracterizem e, como tal, convertam-se em estratégia discursiva, imprimindo sentido(s) e efeito(s) de sentido ao discurso em que se inserem.

Graças principalmente às influências da observação e/ou consideração dos aspectos discursivos da linguagem, reconhece-se como crescente e virtuosa a preocupação com os elementos expressivos resultantes da criação de novas unidades léxicas no discurso literário. E, nesse sentido, adverte Martins (2000, p. 111):

A ideia de que vocábulos que não se incorporam na língua não têm interesse estilístico é bem discutível. Primeiramente, porque não podemos antever o destino dos vocábulos forjados por um escritor ou uma pessoa qualquer. Demais eles evidenciam as potencialidades dos processos de renovação do léxico e dos elementos formadores (lexemas e morfemas), que são integrantes da língua. Ainda que as novas palavras tenham existência efêmera, elas revelam um meio de o falante realizar o seu desejo de expressividade. Muitas delas são realmente de emprego restrito, e não poucas se limitam a uma ou outra ocorrência [...]. Mas, pela sua novidade, causam um inegável efeito expressivo que não se pode menosprezar.

Diante do exposto, para esta análise que se pretende demonstrativa do emprego recursivo de criações lexicais em discurso literário, vale pontuar alguns elementos que contextualizam autor e obra analisados nesse universo.

\section{Autor e obra: apontamentos}

Teoricamente, João Cabral de Melo Neto aparece no contexto da literatura brasileira enquadrado na primeira fase do Modernismo. Considerado pela crítica como um dos maiores poetas brasileiros do século $\mathrm{XX}$, tornou-se (re)conhecido pelo rigor formal de seus versos, herança do pensamento da arte moderna legada de Mallarmé, Valéry, Mondrian, entre outros.

Sua proposta de revalorização do cuidado com a linguagem e de uma expressão poética mais disciplinada, somada a uma perfectibilidade da forma, em relação às primeiras produções da estética modernista, conferem-lhe uma composição originalmente mais racional. Ou, como ele próprio expressa em sua crítica: 
A poesia me parece alguma coisa de muito mais ampla: é a exploração da materialidade das palavras e de possibilidades de organização de estruturas verbais, coisas que não têm nada a ver com o que é romanticamente chamado inspiração ou mesmo intuição. A esse respeito, creio que o lirismo [...] liberou a poesia escrita e não cantada, e permitiulhe que voltasse a operar em territórios que outrora the pertenceram. Fez possível também o exercício da poesia como exploração emotiva do mundo das coisas, e como rigorosa construção de estruturas formais lúcidas, lúcidos objetos de linguagem (MELO NETO, 1998, p. 135).

Em linhas gerais, a temática cultivada por João Cabral gira em torno de suas grandes paixões: o Nordeste brasileiro, onde nasceu e viveu boa parte de sua vida em meio à familia, aos engenhos de cana de açúcar e à seca com suas mazelas; a Espanha, mais especificamente a Andaluzia, onde exerceu funções diplomáticas durante longos anos de sua vida profissional e onde, por admiração e respeito, adquiriu e cultivou influências culturais; o elemento feminino, ao qual se entrega poeticamente, cantando o amor, a paixão, a sedução do corpo e outros prazeres; e, por fim, a própria linguagem, na qual, por procedimento metalinguístico calcado na construção linguístico-discursiva, estão inscritas as criações lexicais.

Mas, sem dúvida, uma das maiores qualidades do poeta é a superação da dicotomia entre expressão e construção. De fato, ele combina estes dois elementos de forma única e rica; na verdade, propõe que a própria construção linguística seja uma forma de expressão. O que certamente consubstancia sua emancipação e a da literatura frente aos seus antecessores.

O fenômeno da construção poética em João Cabral opera-se sob a sua consciência e o seu olhar crítico ora para a própria linguagem, ora para a realidade social ou, em geral, para ambas. Assim, em linhas gerais, sua produção encontra-se sustentada em duas tendências que se articulam: i) a poesia como o resultado de um rigoroso trabalho formal; e, ii) a consciência de que a crítica histórico-social só se torna expressivamente relevante em poesia quando consegue mobilizar uma forma escritural também crítica.

Segundo Alves (2007, p. 8), a construção em João Cabral deve ser compreendida como o caminho por onde operam a constituição metafórico-metonímica e a enunciação da linguagem literária, sendo estas vistas como fatores básicos da constituição da literariedade. E a literariedade é o conjunto de elementos capaz de imprimir o status de literário, por meio da singularização no processo de associação entre forma e conteúdo. Sob essa perspectiva, Alves concebe a engenhosidade cabralina, observando que,

[...] em 'O Engenheiro' [...], mais que um texto sobre o engenheiro e seu trabalho de construção, João Cabral nos apresenta um verdadeiro projeto poético, que seguirá até o fim da sua vida, salvo raríssimas exceções. Sua busca por uma poesia feita a lápis, esquadro e papel, via desenho, projeto e número não o impediu de revelar sua atuação crítica acerca do próprio fazer poético, [...] pois o que ele busca, e alcança (!), é uma associação de forma e conteúdo que nos leva a refletir sobre a própria condição e concepção de literatura na modernidade, que explora tanto os códigos linguísticos, quanto as mensagens que eles podem veicular (ALVES, 2007, p. 3).

Pode-se dizer, portanto, que a construção é um modo particular de (re)elaboração da linguagem literária e que se reconhece nela uma marca de 
expressividade e discursividade na poética cabralina. Ou seja, a engenhosidade cabralina é mais que uma proposta temática do poeta; ela ultrapassa a fronteira do temático e adentra a esfera do estrutural, via metalinguagem.

Ora, esse quadro permite a consideração de que a presença recorrente das criações lexicais na composição poética cabralina e a expressividade por meio delas alcançada são fundamentais também à construção do sentido, de modo a permitirem a inclusão do poeta no rol dos escritores da literatura modernista brasileira que recorrem sistemática e originalmente às criações lexicais (COTRIM, 2012, p. 216).

Tendo em vista, pois, o que tem movido a busca de compreensão da neologia estilística, dos aspectos sociais que, no âmbito da discursividade e da expressividade, a cercam, apresenta-se a seguir um recorte da apreciação das criações e remotivações de lexias textuais na poética de João Cabral.

\section{A expressividade das criações e remotivações de lexias textuais na poética de João Cabral}

No contexto literário, o emprego das lexias textuais, tomado como um recurso discursivo de criação lexical, pode se dar tanto pela criação de uma lexia textual inédita quanto pela remotivação de outras já existentes.

Segundo Barbosa (2001, p. 50), tecnicamente, as criações ou as remotivações de lexias textuais podem ocorrer: i) pela alteração da ordem dos vocábulos integrantes da lexia textual; ii) pela comutação de um dos vocábulos por outro com o qual tenha grande intersecção semêmica; iii) pela substituição de todos ou quase todos os vocábulos integrantes da lexia textual; e iv) pela própria criação de novas unidades léxicas, aos moldes das já existentes.

Entende-se por lexia textual os enunciados cristalizados - ditados, provérbios, frases feitas, sintagmas consolidados, bordões, refrões, etc. - originários de combinatórias livres que, memorizadas, passam a atuar em combinatória fixa, adquirindo um significado global diferente ou não coincidente com o resultante da combinatória livre de seus elementos. A remotivação, por sua vez, consiste em romper a lexicalização ${ }^{5}$ da lexia textual por qualquer tipo de alteração em um ou mais de um dos elementos que a compõem, como se ela estivesse em combinatória livre.

Esse procedimento resulta em grande expressividade pela sutileza principalmente da ironia, no sentido de zombaria, de sarcasmo e de irreverência. Por serem polissêmicos, os produtos desse tipo de construção léxica apresentam, no mínimo, dois designata (significados): o da lexia textual como se acha memorizada, ou seja, a lexia de base, e o gerado na instância discursiva, isto é, a nova lexia.

Aplicadas à composição linguístico-discursiva cabralina, as criações e remotivações de lexias textuais vão ao encontro simétrico da temática proposta pelo poeta em cada contexto e deparam-se com ambiente propício na crítica social e de costumes para a consubstanciação da ironia.

\footnotetext{
5 A lexicalização é o "processo pelo qual determinadas unidades construídas em outros componentes da gramática (sintático, morfológico, discursivo) se transformam em unidades lexicais que se fixam na língua, passando a funcionar como unidades lexicais de pleno direito" (COOREIA; ALMEIDA, 2012, p. 104).
} 
Não só pela estrutura diferenciada e impactante da sua extensão, mas também, e principalmente, pela carga semântica resultante das (re)combinatórias de semas, esse tipo de criação lexical encontrado na poética de João Cabral, embora não represente número significativo em relação aos demais, contribui sobremaneira para a expressividade de sua poética, podendo, inclusive, ser tomado como elemento da sua engenhosidade linguística.

Neste ponto, esta análise chama a atenção para a intersecção entre a criação e a remotivação de lexias textuais na poética cabralina e a já aludida literariedade de que fala Alves (2007).

A literariedade pauta-se na constituição metafórico-metonímica da linguagem literária, na especificidade de sua enunciação e no trabalho estilístico de singularização realizado por cada autor, já que, como sabemos, o valor do texto literário não está naquilo de que trata, mas no como o trata (ALVES, 2007, p. 8, grifo nosso).

Então, para esta análise, pensar a literariedade em João Cabral passa, indubitavelmente, pelo reconhecimento da presença de criações lexicais em sua poética; mas passa, especialmente, pela observação do "modo" como o fenômeno se processa e quais os resultados expressivos que dele emanam dentro da poética cabralina.

Analisando-se detalhadamente o procedimento da literariedade em relação ao objeto estudado, retoma-se, primeiramente, a constituição metafórico-metonímica da linguagem literária e reconhece-se que ela é uma constatação na poética cabralina. Inúmeras análises têm revelado uma alta incidência de metáforas na obra poética de João Cabral e é assim que esta análise se posiciona. Ainda com Alves (2007, p. 12), compreende-se a metáfora como

[...] uma relação verbal que se condensa em uma ideia, uma imagem ou um símbolo e que pode, pelo contato com outras ideias, outras imagens e outros símbolos, tornar-se mais complexa, desencadeando um processo de liberdade sobre a língua e inscrevendo nela a sua subjetividade criativa.

De modo geral, todo procedimento de metaforização é balizado pela motivação de um significado novo a partir de um já existente, contanto que haja uma semelhança entre os elementos de designação. Em outras palavras, geralmente a metáfora é compreendida como um desvio da significação de um signo a partir de uma comparação mental entre, no mínimo, dois elementos, cuja interação se faz evidente. A relação de transferência dos sentidos entre o elemento A e o elemento B permite a fixação de uma nova pertinência semântica. No caso específico das criações e remotivações de lexias textuais cabralinas, elas revelam nitidamente a relação do significado ou sentido alcançado no contexto com o da lexia textual já memorizada, mas avançam no processo de metaforização sempre a buscar novos sentidos, quantas forem as novas leituras.

No que se refere ao segundo elemento da literariedade, ou seja, à especificidade da enunciação no discurso cabralino, vale levar em consideração alguns pontos, o que se faz a partir da exploração do conceito de enunciação. Entende-se por enunciação a colocação da língua em funcionamento por um ato individual de sua utilização (BENVENISTE, 2006, p. 2), pelos procedimentos de actorialização, espacialização e temporalização na instância da enunciação. Ou seja, é o ato de instauração da língua pelas projeções das categorias de pessoa, de lugar e de tempo no ato de linguagem. 
Chama-se a atenção, aqui, novamente, e isso é o que importa nesse particular para esta análise, que a enunciação, apesar de ocorrer tanto para a língua comum quanto para a literária, naquela ela reflete a ação, a paráfrase, visto que ali a comunicação se prende ao dizer em si e ao sentido que esse dizer evoca quando remete à ação; ao passo que nesta, o foco da comunicação volta-se para a relação entre o dizer e o dito, entre a enunciação e o enunciado. Isto é, volta-se para o "modo" como se diz. Por esse prisma, num sentido amplo, a enunciação na poética cabralina ganha em qualidade ao explorar o senso crítico do enunciador, em primeira instância, e da habilidade (meta)linguística do autor, em segunda instância, produzindo o efeito de realidade desejado em sua crítica social.

Quanto ao último elemento da literariedade, ou seja, o trabalho estilístico de singularização realizado pelo autor, cumpre retomar o aspecto da expressividade na/da literatura e, de modo específico, das criações lexicais literárias. A expressividade, segundo Cardoso (2004, p. 151; 2009, p. 69), pode ser compreendida como o resultado de um desvio estilístico, isto é, como outras formas de se dizer o que já foi dito e repetido.

Essa concepção direciona a discussão mais uma vez para a importância, no universo literário, do "como" se diz, em detrimento do que se diz. Ora, todo processo de operacionalização particularizada da língua, tal como se dá na linguagem literária, tem resultado singular, com traço de personalidade imanente no conceito de estilo. Enfim, é desta língua, a que transcende o plano intelectivo para buscar a expressão, que se entende emanar o ato linguístico em que repousa a enunciação cabralina.

Diante do exposto, a seguir são apresentados alguns exemplos dos casos de criação e remotivação de lexias textuais cabralinas, com a interpretação da expressividade e do efeito de sentido em seus contextos discursivo-enunciativos, seguidos das respectivas abonações.

Primeiramente, apresentam-se dois casos considerados nesta análise como criações de lexias textuais na poética cabralina, quais sejam os exemplos (01) e (02).

sobrar da vara do pão

No contexto, esta unidade léxica textual significa "o excesso dos dias em relação ao que se dispõe de alimento durante um período estipulado". Isto é, sobram dias e faltam provisões. Ou ainda, a unidade léxica textual refere-se a uma situação em que não se tem alimento suficiente para durar até que se possa adquirir novas provisões.

\section{mais comprido que fio de tecelão}

Em consonância com a anterior, esta outra unidade léxica textual pode ser entendida como "a passagem lenta das horas de quem não tem o que fazer e pouco dispõe do que comer". Isto é, ela indica que os dias de quem tem fome são percebidos ou sentidos, dada a dificuldade de se suportar a situação, como mais longos.

Ambas as unidades supra arroladas figuram o mesmo contexto e formam um bloco de sentido em que o enunciador faz referência à obra poética de Joan Brossa. ${ }^{6}$

\footnotetext{
6 Joan Brossa i Cuervo foi um poeta modernista espanhol inspirador e um dos fundadores do grupo e da publicação conhecida como Dau al Set (1948), tida como uma das principais manifestações modernas da
} 
Juntas, elas representam situações do dia a dia das pessoas que vivem em bairros economicamente desfavorecidos da cidade de L'Hospitalet de Llobregat, na Catalunha, considerada a região industrial e suburbana de Barcelona, onde a maioria da população se vale de poucas condições para suprir suas necessidades básicas de forma completa e adequada e na qual passa a viver o referido poeta.

No enunciado, elas compõem o discurso da miséria de grande parte da classe artística cuja produção ainda não alcançou visibilidade e cuja adversidade conduz à consciência crítica. Discurso este que atravessa o da denúncia social. Ou seja, segundo o enunciador, são exatamente essas condições de miserabilidade em que vive o poeta Joan Brossa ao mudar-se para L'Hospitalet que o levam a refletir e, por conseguinte, a produzir uma obra mais complexa, mais profunda e, em tese, de maior valor crítico.

Abonação: "Mas porém como buscava / onde é o sol mais temporão, / pelo Clot. Hospitalet, onde as semanas / sobram da vara do pão / e o horário é mais comprido / do que fio de tecelão, / acabou vendo, Joan Brossa, / que os verbos do catalão / tinham coisas por detrás / eram só palavras, não." (PCF, VI, p. 124-125).

Os exemplos (03), (04) e (05) são considerados nesta análise casos de remotivações de lexias textuais já existentes no léxico da língua portuguesa e se consolidam na poética cabralina exclusivamente pela comutação de um dos elementos do bloco por outro com o qual ele apresenta uma intersecção semêmica metafórica.

$$
\text { sede de palha }
$$

Esta unidade criada pelo processo de remotivação de lexia textual já existente faz referência, no enunciado, ao curso ("viagem") do rio Capibaribe desde a sua cabeceira, na serra do Jacarará, até a cidade do Recife, onde desemboca. Observado o fluxo natural do rio, nota-se que ele nasce numa região agreste onde a seca predomina e vai ter sua foz no mar, onde, naturalmente, não há aridez.

Considerado o contexto, a unidade criada remete o enunciatário à sede metafórica do rio e à sede natural de todo retirante que acompanha o seu curso para chegar ao seu destino. Para ambos a sede começa renitente mas vai diminuindo à medida em que eles - rio e retirante - aproximam-se da Zona da Mata, onde o clima é mais ameno, a seca é mais branda e o rio vai-se tornando mais caudaloso.

Tendo em vista este fato, reconhece-se como lexia textual de base para a remotivação a unidade lexicalizada "fogo de palha", que significa "fogo forte, mas fugaz".

A remotivação acontece, portanto, sugerindo que essa sede do retirante que, a princípio, é voraz torna-se passageira se se faz a retirada do agreste para a Zona da Mata acompanhando o curso do rio. Isto é, uma "sede de palha" é aquela que, embora a princípio seja intensa, logo se acaba.

O enunciado mostra, paralelamente ao discurso da miséria renitente do sertanejo, a importância do Rio Capibaribe na geografia e na vida pernambucanas, visto que

arte catalã. É considerado um poeta total sem distinção de gêneros, visto que seu trabalho abarca poesia, prosa poética, poesia visual, cinema, teatro, música, cabaré, design gráfico, mágica e circo. Escreveu só na sua língua natal, a catalã (In: 〈http://pt.wikipedia.org/wiki/Joan_Brossa〉. Acesso em 08 fev. 2012). 
representa uma possibilidade de mudança de condição econômica e social, entre outras, para o retirante ou para quem dele venha a se beneficiar.

Abonação: "Rio menino, eu temia / aquela grande sede de palha, / grande sede sem fundo / que águas meninas cobiçava. / Por isso é que ao descer / caminho de pedras eu buscava, / que não leito de areia / com suas bocas multiplicadas. / Leito de pedra abaixo / rio menino eu saltava. / Saltei até encontrar / as terras fêmeas da Mata." (OR, VI, p. 89).

(04) sol de dois canos

Esta unidade é remotivada a partir da unidade lexicalizada "espingarda de dois canos" que designa um tipo de arma de fogo, cuja constituição dupla de canos, sobrepostos ou paralelos, disponibiliza a utilização de dois projéteis que podem ser disparados simultânea ou repetidamente, de modo a permitir o aumento da potência da explosão e da extensão dos seus resultados, ou danos.

No contexto, a unidade criada designa o sol típico de Pernambuco que pela sua intensidade reflete tanto as ações de clarear intensamente, quanto de, metaforicamente, incendiar a terra. O fenômeno parece estar ligado ao fato de o estado pernambucano localizar-se, geograficamente, próximo ao ponto mais leste do continente sul americano e, como o sol nasce também a leste deste continente, esta porção de terra recebe primeira e incidentemente a luz solar em relação aos demais pontos dele. Isso justifica, para o enunciador, a intensidade da luz do sol, a sua incidência e respectivas consequências e sugere as metáforas da sede, do sofrimento e, até, da morte, que revelam ou desvelam a dura realidade daquela terra e daquela gente. Ou seja, assim como a arma de dois canos, que ao repetir o tiro provoca maior estrago, este tipo de sol, isto é o "sol de dois canos", pela duplicação (ou multiplicação, talvez) de sua ação, torna-se arrasador, quase insuportável, e ocasiona a intempérie da seca com suas mazelas: a fome, a miséria, a morte, entre outras, para as quais pouco ou nada se tem feito politicamente.

Nesse caso, o discurso da miséria é atravessado pelo discurso da conformação, da passividade, da aceitação do sertanejo de sua miserabilidade, de seu infortúnio diante de um evento que acaba por considerar natural e corriqueiro e para o qual nem ele espera solução.

Abonação: "O sol em Pernambuco leva dois sóis, / sol de dois canos, de tiro repetido; / o primeiro dos dois, o fuzil de fogo, / incendeia a terra: tiro de inimigo. [...] // $\mathrm{O}$ sol em Pernambuco leva dois sóis, / o sol de canos, de tiro repetido; / o segundo dos dois, o fuzil de luz, revela real a terra; tiro de inimigo." (AEPP, VII, p. 28-29).

(05) ditar as canas de seu tempo

Esta é uma remotivação da frase feita "ditar as regras de seu tempo" que significa "impor ou prescrever as normas que vigoram ou devem vigorar num determinado contexto sócio-histórico ou área". No contexto, a remotivação faz referência à atitude do ilustre Joaquim $\operatorname{Cardozo}^{7}$ que, segundo o enunciador, dado o seu

\footnotetext{
7 Joaquim Cardozo foi poeta, contista, desenhista, engenheiro civil, professor universitário e editor de revistas especializadas em arte e arquitetura. De naturalidade pernambucana, notabilizou-se pela sua
} 
conhecimento, perspicácia e notabilidade, mesmo sendo urbano, mais precisamente um "recifense de praia", domina a temática dos engenhos de açúcar e, empregando-a habilmente em suas obras, influencia até quem é do ramo ou um "cria de engenho" e, portanto, conhecedor do assunto.

Esta unidade léxica remete o enunciatário ao discurso do latifúndio canavieiro que atravessa o discurso da miséria sertaneja pernambucana, haja vista a subjugação do sertanejo às grandes plantações de cana, à máquina, aos engenhos, ao coronelismo e, consequentemente, às condições deploráveis de trabalho que the são impostas neste contexto.

Abonação: "De calça e paletó de amianto, / ei-lo entre os cantados encantos, / sem sentir que esse mar que o cerne / é o Atlântico do Nordeste: // De Guarabira, Pirangi, / Carne de Vaca, Serrambi. / Recifense, a um cria de engenho, / ditou as canas de seu tempo" (CCR, VII, p. 324).

\section{Considerações finais}

Pela análise observou-se que as criações e remotivações de lexias textuais encontradas na poética de João Cabral de Melo Neto promovem uma expressividade única que confirma a percepção do modo como o poeta concebe a sua poesia. Isto é, que a expressividade na poética cabralina se dá tanto pela temática abordada quanto pela própria técnica linguística ou, neste caso específico, pelos processos de construção de palavras em si e respectivos efeitos de sentido.

As criações e remotivações de lexias textuais refletem no fazer poético cabralino aquilo que o poeta considera como manipulação da linguagem ou como "construção". Compreende-se, portanto, que elas são concebidas por ele como um trabalho formal capaz de expressar a crítica histórico-social não só por meio do conteúdo, mas também pela sua forma escritural.

Além disso, nesta análise procurou-se demonstrar que os efeitos de sentido alcançados pelas criações e remotivações de lexias textuais, compreendidas no discurso poético cabralino como a referida forma de manipulação da linguagem, são perpassados pela ironia e irreverência que deste mecanismo resultam. Como peças importantes do enunciado, elas vão ao encontro simétrico da temática abordada em cada contexto em que se inserem e naquilo que é enunciado. Em outras palavras, as particularidades que definem o modo de construção da linguagem na poética cabralina, seja na criação ou na remotivação das lexias textuais, nesta sobretudo pela comutação e ou (re)combinatória de semas, garantem a ironia e a irreverência e estas participam sobremaneira da constituição dos juízos de valor sobre aspectos culturais, sociais, históricos ou outros da vida humana e da sua relação com o meio.

A análise aponta, enfim, que a engenhosidade do poeta pode ser reconhecida também pelas criações lexicais presentes em sua obra e que elas tanto contribuem com o seu cunho crítico, quanto corroboram a qualidade de sua poesia enquanto legítima representante da superação da dicotomia entre expressão e construção e, por conseguinte, do procedimento de literariedade. 


\section{REFERÊNCIAS}

ALVES, I. M. Neologismo: criação lexical. 2. ed. São Paulo: Ática, 2002.93 p.

ALVES, W. da S. A linguagem literária do poeta engenheiro: um estudo de Sevilha Andando de João Cabral de Melo Neto. Espéculo - Revista de Estudos Literários da Facultad de Ciencias de la Información, Universidad Complutense de Madrid, n. 36, jul.-out. 2007. Não paginado. Disponível em <http://www.red-redial.net/revistaespeculo,revista,de,estudios, literarios-268-2007-0-36.html>. Acesso em: 16 mai. 2011.

BARBOSA, M. A. Léxico, produção e criatividade: processos do neologismo. São Paulo: Global Editora, 1981. 323 p.

Da neologia à neologia na literatura. In: OLIVEIRA, A. M. P. P. de; ISQUERDO, A. N. (org.). As ciências do Léxico: Lexicologia, Lexicografia e Terminologia. v. 1. 2. ed. Campo Grande: Ed. da UFMS, 2001. p. 33-51.

BAKHTIN, M. (Volochínov, 1929). Marxismo e filosofia da linguagem. Tradução de Michel Lahud e Yara Frateschi Vieira. 8. ed. São Paulo: Hucitec, 1997. 196 p.

Teoria do romance I: A estilística. Tradução de Paulo Bezerra. São Paulo: Editora 34, 2015. 254 p.

BASTUJI, J. Notes sur la créativité lexicale. In: BASTUJI, J. et al. (org.). Néologie e Lexicologie. Paris: Larousse, 1979. p. 12-20.

BENVENISTE, É. O aparelho formal da enunciação. In: linguística geral. v. II. 2. ed. Campinas: Pontes, 2006. p. 81-90.

Problemas de

CÂMARA JR., J. M. Contribuição à estilística portuguesa. Rio de Janeiro: Ao Livro Técnico Editora, 2004. 79 p.

CARDOSO, E. de A. A criação neológica estilística. Revista Matraga do Programa de Pós-Graduação em Letras da Universidade do Estado do Rio de Janeiro. Rio de Janeiro, p. 147-162, ano 11, n. 16. 2004. Disponível em $\langle$ http $/ /$ wwwpgletras.uerj.br/matraga/matraga16/matraga16a13pdf $>$. Acesso em: 16 mai. 2011.

A poesia: escolha lexical e expressividade. In: CARDOSO, E. de A.; GIL, B. D.; CONDÉ, V. G. (org.). Modelos de análise linguística. São Paulo: Editora Contexto, 2009. p. 67-78.

CORREIA, M.; LEMOS, L. S. P. de. Inovação lexical em português. v. 4. Lisboa: Edições Colibri, 2009. 94 p.

CORREIA, M.; ALMEIDA, G. M. de B. Neologia em português. São Paulo: Parábola Editorial, 2012. $111 \mathrm{p}$.

COTRIM, R. M. S. As Criações Lexicais na Poética de João Cabral de Melo Neto: contribuições aos estudos do léxico no discurso literário. 2012. 231 f. Tese (Doutorado em Linguística e Língua Portuguesa) - Faculdade de Ciências e Letras de Araraquara, Universidade Estadual Paulista, Araraquara.

FERREIRA, A. B. de H. Novo Dicionário da Língua Portuguesa. Rio de Janeiro: Nova Fronteira, 1971. $2222 \mathrm{p}$. 
Dicionário Aurélio da Língua Portuguesa. Versão eletrônica 7.0, 2010 (Edição comemorativa aos cem anos de Aurélio Buarque de Holanda Ferreira). 1 CD-ROM.

. Dicionário Aurélio da Língua Portuguesa. 5. ed. Curitiba: Editora Positivo, 2010 (Edição comemorativa aos cem anos de Aurélio Buarque de Holanda Ferreira).

GUILBERT, L. La créativité lexicale. Paris: Librairie Larousse, 1975. 285 p.

HOUAISS, A. Dicionário Houaiss da Língua Portuguesa. Versão eletrônica 3.0, 2009. 1 CD-ROM.

JAUSS, H. R. A estética da recepção: colocações gerais. In: LIMA, L. C. C. A literatura e o leitor: textos de estética da recepção. 2. ed. São Paulo: Paz e Terra, 2002. p. 98-112.

MARTINS, N. S. Introdução à Estilística: a expressividade na língua portuguesa. 3. ed. São Paulo: T. A. Queiroz Editor, 2000. 259 p.

MELO NETO, J. C. de. A educação pela pedra e depois. v. 1. Rio de Janeiro: Nova Fronteira, 1997a. 385 p.

Serial e antes. v. 2. Rio de Janeiro: Nova Fronteira, 1997b. 325 p. Prosa. Rio de janeiro: Nova Fronteira, 1998. 139 p.

Recebido em: 04/10/2015

Aprovado em: 18/04/2016 